\title{
Prescribing patterns of coronary artery aneurysm in Taiwan
}

\author{
Chun-Hui Lu ${ }^{1+}$, Chih-Wun Fang ${ }^{1+}$, Hao-Ming Chen ${ }^{1,2}$, Yi-Ping Fang ${ }^{3}$, Chein-Tang Fang ${ }^{3}$, Yaw-Bin Huang ${ }^{3,4}$, \\ Chung-Yu Chen ${ }^{3,4,5^{*}}$, Kuang-Ming Liao ${ }^{6^{*}}$ (D) and Shu-Chuan Jennifer Yeh ${ }^{7}$
}

\begin{abstract}
Background: Coronary artery aneurysm (CAA) is a rare disease, and there are limited data on prescribing patterns for CAA. The aim of our study was to investigate prescribing patterns for CAA in Taiwan via the National Health Insurance Research Database (NHIRD).

Methods: We included all CAA patients in Taiwan from 2005 to 2011. Data from 1 year before and after the CAA diagnosis were used to analyze examinations, comorbidities and prescribing patterns.

Results: A total of 1397 patients diagnosed with CAA were enrolled in our study. Most pediatric patients with CAA were diagnosed with Kawasaki disease (95.7\%). In pediatric CAA patients, the utilization rates of aspirin and gamma globulins were 82.9 and 53.6\%, respectively, after CAA diagnosis. Among the antithrombotic agents, aspirin was used most commonly, followed by dipyridamole (16.9\%), heparin (5.8\%) and warfarin (4.6\%). In adult CAA patients, common comorbidities included hypertension (63.4\%), hyperlipidemia (39.6\%), and diabetes mellitus (26.1\%). Coronary atherosclerosis was identified in $72.5 \%$ of adult patients after CAA diagnosis. Antithrombotic agents, particularly aspirin, clopidogrel and heparin, were prescribed more frequently after CAA diagnosis. Among the prescribed medications, aspirin (75.8\%), $\beta$-blockers (48.3\%), statins (47.6\%), metformin (14.4\%), sulfonylureas (14.4\%) and isosorbide mononitrate (32.9\%) were frequently observed in each category.

Conclusions: Kawasaki disease was the main cause of CAA in pediatric patients, and coronary artery disease was the most common comorbidity in adult CAA patients. The most commonly used antithrombic agent after CAA diagnosis was aspirin in both adult and pediatric patients.
\end{abstract}

Keywords: Comorbidities, Coronary artery aneurysm, Prescribing pattern

\section{Background}

Coronary artery aneurysm (CAA) is a rare disease that can manifest at any age; CAA was first described by Morgagni in 1761. [1] Typically, CAA is identified accidentally during diagnostic coronary angiography when patients have ischemic syndromes. CAA is defined as a dilatation of the blood vessel in which the luminal diameter exceeds more than 1.5-fold the size of the normal adjacent segments or the largest coronary vessel based on the Coronary Artery Surgery Study (CASS) registry [2].

\footnotetext{
* Correspondence: jk2975525@hotmail.com; abc8870@yahoo.com.tw

${ }^{3}$ School of Pharmacy, Kaohsiung Medical University, 100, Shiquan 1st Rd., Sanmin Dist.,, Kaohsiung City 80708, Taiwan, Republic of China

${ }^{6}$ Department of Internal Medicine, Chi Mei Medical Center, Chiali, No.606,

Jialixing, Jiali Dist., Tainan City 72263, Taiwan, Republic of China

Full list of author information is available at the end of the article
}

The incidence of CAA varies widely, from 0.3 to $5.3 \%$ based on the literature [3-10]. Even though the prognosis of patients with CAA is generally good, CAA can cause ischemic syndrome with the presentation of angina, myocardial infarction or even sudden death. [1113] CAA is primarily caused by atherosclerosis and Kawasaki disease in adults and children, respectively [14-16]. Other causative factors include connective tissue disorders, [17] congenital anomalies, infection, specific drug reactions, trauma or iatrogenic interventions [18]. Currently, there are no consensus guidelines for the management of CAA, except for the population with Kawasaki disease [19]. CAA treatment options include medical, surgical and percutaneous interventions. Medical therapy with antiplatelet or anticoagulant drugs seems to be beneficial for preventing thrombus

(c) The Author(s). 2019 Open Access This article is distributed under the terms of the Creative Commons Attribution 4.0 International License (http://creativecommons.org/licenses/by/4.0/), which permits unrestricted use, distribution, and 
formation and distal embolization in patients with CAA $[20,21]$. Some authors have indicated that statins may be beneficial in such a population based on the high ratio of atherosclerotic disease [22].

Antiplatelet and anticoagulant therapy may be necessary if thrombosis or embolism is a concern [21]. Until now, there have been limited data on prescribing patterns for CAA, and the aim of our study was to investigate the prescribing patterns for CAA in Taiwan via the National Health Insurance Research Database (NHIRD).

\section{Methods}

\section{Data source}

We performed a population-based retrospective study using data from the NHIRD in Taiwan. The National Health Insurance program was established in 1995, and more than $99.9 \%$ of Taiwan's population was enrolled as of 2014. By applying to the National Health Insurance Research Institutes for the specific subject datasets of CAA, we obtained data for the whole CAA population in Taiwan and permission to use it to investigate the epidemiology and prescribing patterns for CAA.

All medical records, including outpatient care, inpatient care, emergency care and prescriptions, were utilized for the analysis in the current study.

\section{Population}

To identify patients diagnosed with CAA, we use the International Classification of Diseases, Ninth Revision, Clinical Modification (ICD-9-CM) code 414.11, and we selected patients from 2005 to 2011. Data from 1 year before and after the CAA diagnosis was used to analyze examinations, comorbidities and prescribing patterns. Patients who had 2 outpatient diagnoses or 1 inpatient diagnosis between January 1, 2005, and December 31, 2011, were enrolled. The index date was defined as the date of the first diagnosis of CAA. As CAA was identified with the assistance of imaging by coronary angiography, echocardiography (echo), computed tomography (CT), magnetic resonance imaging (MRI) or during cardiac catheterization, patients with CAA received one of the above examinations as confirmation. In our study, we defined patients who received one of the examinations, including coronary angiography, echo, CT, MRI, and cardiac catheterization, within 90 days before or after the index date as having CAA.

For evaluation of concomitant disease, patients were divided into two groups, pediatric and adult populations, considering the difference in the nature of the disease. In the current study, we defined the pediatric population as patients younger than 20 years of age and the adult population as patients older than 20 years of age.

This study was approved by the Institutional Review Board of the Kaohsiung Medical University Hospital
(KMUHIRB-EXEMPT-20130199) and Kaohsiung Armed Forces General Hospital (KAFGH 106-039). Informed consent was waived because patient data were deidentified by scrambling the identification codes.

\section{Prescribing patterns}

We recorded the medication use in the population and identified drugs administered 1 year before and after the index date by the Anatomical Therapeutic Chemical (ATC) Classification System. To investigate the usage of antithrombotic agents, prescriptions of common antiplatelets and anticoagulants used before or after the diagnosis of CAA were recorded and presented as numbers and proportions (\%). In the analysis, antithrombotic agents included aspirin, clopidogrel, dipyridamole, ticlopidine, tirofiban, cilostazol, warfarin, heparin and enoxaparin. Oral drugs for cardiovascular disease, including antithrombotic agents, antihypertensive agents, antidyslipidemic agents, antidiabetic agents and nitrates, were also investigated.

\section{Statistical analysis}

Age is presented as years (means \pm standard deviations) and is divided into 3 groups: younger than 20 years, 20 64 years and older than 65 years. The detailed age distribution of the pediatric and adult populations is shown as a bar chart. Gender and other demographic information, including area, urbanization, and insurance premiums, is presented as numbers and proportions (\%). Data processing and statistical analyses were performed with the use of SAS version 9.4 (SAS Inc., Cary, NC).

\section{Results}

\section{Study population}

There were 1493 patients with at least 2 CAA diagnoses at the outpatient department or 1 CAA diagnosis at the inpatient department from 2005 to 2011. After excluding 96 patients without any record of related examinations, a total of 1397 patients with CAA during 2005 to 2011 were identified and enrolled in our study. Patient characteristics are shown in Table 1. Among the 1397 CAA patients, the mean age was $37.76 \pm 31.45$ years. There were $586(41.9 \%)$ pediatric patients aged less than 20 years, $430(30.8 \%)$ adult patients aged 20 to 65 years and 381 (27.3\%) adult patients aged 65 years and older.

Table 2 shows the medical procedures of the CAA population. Most adult patients (75.4\%) underwent cardiac catheterization, and as high as $98 \%$ of pediatric patients received echo.

\section{Comorbidities}

Regarding the comorbidities of patients with CAA, we analyzed the 10 most common concomitant diseases based on different age groups (i.e., pediatric versus adult 
Table 1 Baseline characteristics of the CAA population in

Taiwan

\begin{tabular}{|c|c|}
\hline Variable $(N=1397)$ & Number (\%) \\
\hline Age, year (mean $\pm S D)$ & $37.76 \pm 31.45$ \\
\hline \multicolumn{2}{|l|}{ Age group (year) } \\
\hline$<20$ & $586(41.9)$ \\
\hline $20-64$ & $430(30.8)$ \\
\hline$\geq 65$ & $381(27.3)$ \\
\hline \multicolumn{2}{|l|}{ Gender } \\
\hline Male & $957(68.5)$ \\
\hline Female & $440(31.5)$ \\
\hline \multicolumn{2}{|l|}{ Area } \\
\hline North & $546(39.1)$ \\
\hline Central & $518(37.1)$ \\
\hline South & $307(22.0)$ \\
\hline East & $26(1.9)$ \\
\hline \multicolumn{2}{|l|}{ Urbanization } \\
\hline Urbanized & $1019(72.9)$ \\
\hline Rural & $378(27.1)$ \\
\hline \multicolumn{2}{|l|}{ Intervention } \\
\hline $\mathrm{PCl}$ & $102(7.3)$ \\
\hline CABG & $5(0.4)$ \\
\hline \multicolumn{2}{|c|}{ Monthly insurance premiums (NTD) } \\
\hline$<20,000$ & $1030(73.7)$ \\
\hline $20,000-39,999$ & $273(19.5)$ \\
\hline$\geq 40,000$ & $94(6.7)$ \\
\hline
\end{tabular}

NTD New Taiwan Dollars, $P C l$ percutaneous coronary intervention, $C A B G$ Coronary artery bypass grafting populations) and time frames (i.e., within 1 year before and after CAA diagnosis) to observe the disease status over time (Table 3 ). In the pediatric population, common coexisting diseases included acute upper respiratory infections (e.g., sinusitis, bronchitis and pharyngitis), acute febrile mucocutaneous lymph node syndrome (i.e., Kawasaki disease), noninfectious gastroenteritis and colitis and skin-related disorders. Notably, Kawasaki disease increased very quickly to a high level of frequency after the diagnosis of CAA; $95.7 \%$ of the pediatric population was diagnosed with Kawasaki disease.

In the adult population, most of the comorbidities before CAA diagnosis were chronic diseases. Cardiovascular diseases, such as coronary artery disease (65.7\%), hypertension (63.4\%), dyslipidemia (39.6\%) and diabetes $(26.1 \%)$, were very common in this population. The rates of several coexisting diseases were higher after the index date than before, among which coronary atherosclerosis predominated, with an increase from 33.8 to $72.5 \%$ after CAA diagnosis.

\section{Prescribing patterns}

The prescribing patterns in the CAA population were divided into 2 categories, the utilization of antithrombotic agents (Table 4) and long-term medications for cardiovascular diseases in adults (Table 5).

In the pediatric population, the usage of aspirin $(82.9 \%)$ and gamma globulins (53.6\%) increased after CAA diagnosis, which reflected the need to attenuate inflammation of the vessels and prevent thrombosis in patients with Kawasaki disease. For antithrombotic agents, the most frequently used antiplatelet agent in the pediatric population was aspirin, followed by dipyridamole. A small proportion of pediatric patients had been prescribed warfarin and heparin. The prescribing rates of antithrombotic agents increased after CAA diagnosis in the pediatric population (Fig. 1).

Table 2 Procedures received in the CAA population

\begin{tabular}{llll}
\hline Procedure & Age $<20$ years $(n=592)$ & Age $\geq 20$ years $(n=901)$ & All population $(n=1493)$ \\
\hline Single item & & & $447(29.9 \%)$ \\
Angio & $42(7.1 \%)$ & $405(45.0 \%)$ & $738(49.4 \%)$ \\
Cath & $59(10.0 \%)$ & $679(75.4 \%)$ & $1158(77.6 \%)$ \\
Echo & $580(98.0 \%)$ & $578(64.2 \%)$ & $252(16.9 \%)$ \\
CT & $42(7.1 \%)$ & $210(23.3 \%)$ & $55(3.7 \%)$ \\
MRI & $7(1.2 \%)$ & $48(5.3 \%)$ & $740(49.6 \%)$ \\
Multiple items & & & $1365(91.4 \%)$ \\
Angio or Cath & $60(10.1 \%)$ & $680(75.5 \%)$ & $1397(93.6 \%)^{\mathrm{a}}$ \\
Angio or Cath or Echo & $586(99.0 \%)$ & $779(86.5 \%)$ & $811(90.0 \%)$ \\
Angio or Cath or Echo or CT or MRI & $586(99.0 \%)$ & & \\
\hline
\end{tabular}

a Final population included in the epidemiological study

Angio coronary angiography, Cath cardiac catheterization, Echo echocardiography, CT computed tomography, MRI magnetic resonance imaging 
Table 3 Comorbidities of CAA patients before and after CAA diagnosis

\begin{tabular}{|c|c|c|}
\hline Comorbidity & $\begin{array}{l}1 \text { year before index date } \\
\mathrm{N}(\%)\end{array}$ & $\begin{array}{l}1 \text { year after index date } \\
\mathrm{N}(\%)\end{array}$ \\
\hline \multicolumn{3}{|l|}{ Pediatric population, aged $<20$ years $(N=586)$} \\
\hline Kawasaki disease & $243(41.5)$ & $561(95.7)$ \\
\hline Acute respiratory infections & $540(92.2)$ & $556(94.9)$ \\
\hline Noninfectious gastroenteritis and colitis & $163(27.8)$ & $160(27.3)$ \\
\hline Pneumonia & $82(14.0)$ & $122(20.8)$ \\
\hline Allergic rhinitis & $66(11.3)$ & $97(16.6)$ \\
\hline Contact dermatitis & $98(16.7)$ & $80(13.7)$ \\
\hline Urinary tract infection & $70(11.9)$ & $66(11.3)$ \\
\hline Atopic dermatitis & $63(10.8)$ & $55(9.4)$ \\
\hline Influenza & $35(6.0)$ & $47(8.0)$ \\
\hline Infectious colitis, enteritis and gastroenteritis & $37(6.3)$ & $38(6.5)$ \\
\hline \multicolumn{3}{|l|}{ Adult population, age $\geq 20$ years $(N=811)$} \\
\hline Coronary artery disease & $533(65.7)$ & $704(86.8)$ \\
\hline Coronary atherosclerosis & $274(33.8)$ & $588(72.5)$ \\
\hline Hypertension & $514(63.4)$ & $561(69.2)$ \\
\hline Dyslipidemia & $321(39.6)$ & $399(49.2)$ \\
\hline Diabetes mellitus & $212(26.1)$ & $255(31.4)$ \\
\hline Angina & 153 (18.9) & $238(29.3)$ \\
\hline Heart failure & $107(13.2)$ & $171(21.1)$ \\
\hline Arrhythmia & $131(16.2)$ & 159 (19.6) \\
\hline Myocardial infarction & $84(10.4)$ & $152(18.7)$ \\
\hline Chronic obstructive pulmonary disease & $127(15.7)$ & $139(17.1)$ \\
\hline
\end{tabular}

Table 4 Antithrombotic agents used in the CAA population before and after CAA diagnosis

\begin{tabular}{|c|c|c|c|c|}
\hline & \multirow{3}{*}{$\begin{array}{l}\text { Before index date } \\
1 \text { year } \\
\mathrm{N}(\%)\end{array}$} & \multicolumn{3}{|c|}{ After index date } \\
\hline & & 3 month & 6 month & 1 year \\
\hline & & N (\%) & N (\%) & N (\%) \\
\hline \multicolumn{5}{|c|}{ Pediatric population $(N=586)$} \\
\hline Aspirin & $182(31.1)$ & $479(81.7)$ & $482(82.3)$ & $486(82.9)$ \\
\hline Clopidogrel & $1(0.2)$ & $4(0.7)$ & $4(0.7)$ & $4(0.7)$ \\
\hline Dipyridamole & $43(7.3)$ & $95(16.2)$ & $97(16.6)$ & 99 (16.9) \\
\hline Warfarin & $7(1.2)$ & $25(4.3)$ & $26(4.4)$ & $27(4.6)$ \\
\hline Heparin & $5(0.9)$ & $31(5.3)$ & $33(5.6)$ & $34(5.8)$ \\
\hline \multicolumn{5}{|c|}{ Adult population $(N=811)$} \\
\hline Aspirin & $575(70.9)$ & $667(82.2)$ & $678(83.6)$ & $689(85.0)$ \\
\hline Clopidogrel & $256(31.6)$ & $510(62.9)$ & $514(63.4)$ & $523(64.5)$ \\
\hline Dipyridamole & $127(15.7)$ & $81(10.0)$ & $94(11.6)$ & $108(13.3)$ \\
\hline Ticlopidine & $32(3.9)$ & $26(3.2)$ & $31(3.8)$ & $36(4.4)$ \\
\hline Tirofiban & $22(2.7)$ & $28(3.5)$ & $28(3.5)$ & $29(3.6)$ \\
\hline Cilostazol & $20(2.5)$ & $26(3.2)$ & $29(3.6)$ & $41(5.1)$ \\
\hline Warfarin & $60(7.4)$ & $126(15.5)$ & $132(16.3)$ & $141(17.4)$ \\
\hline Heparin & $164(20.2)$ & $551(67.9)$ & $562(69.3)$ & $577(71.1)$ \\
\hline Enoxaparin & $60(7.4)$ & $131(16.2)$ & $140(17.3)$ & 147 (18.1) \\
\hline
\end{tabular}

In the adult population, which differed from the pediatric population, antiplatelets (aspirin, clopidogrel) and nitrates (nitroglycerin, isosorbide 5-mononitrate) were frequently prescribed before CAA diagnosis in adults owing to underlying chronic diseases. Furthermore, aspirin, clopidogrel and heparin usage increased both in frequency and average amount after CAA diagnosis (Fig. 2).

Among the antiplatelet agents, the prescribing rate of aspirin was the highest, followed by clopidogrel, dipyridamole and other drugs. For anticoagulants, heparin was the most often prescribed; as many as $71.1 \%$ of adult patients had taken heparin. Nearly all antithrombotic agents, except for dipyridamole, had higher prescribing rates after CAA diagnosis than before (Table 4).

Considering the high proportion of cardiovascular disease in adults, we evaluated related oral drugs in long-term use. Table 5 shows the prescribing rates of each class of medication. As a whole, every kind of medication tended to increase after CAA diagnosis, except antidiabetic agents, which slightly decreased (Table 5). The most frequently prescribed drugs among each class were aspirin, $\beta$-blockers, statins, sulfonylureas (equal to metformin 1 year after index date) and isosorbide mononitrate. 
Table 5 Medication used in the CAA population before and after CAA diagnosis

\begin{tabular}{|c|c|c|c|c|}
\hline & \multirow{2}{*}{$\begin{array}{l}\text { Before index date } \\
1 \text { year }\end{array}$} & \multicolumn{3}{|c|}{ After index date } \\
\hline & & 3 month & 6 month & 1 year \\
\hline$N=811$ & $\mathrm{~N}(\%)$ & N (\%) & N (\%) & $N(\%)$ \\
\hline Antithrombotic agent & $555(68.4)$ & $680(83.8)$ & $700(86.3)$ & $722(89.0)$ \\
\hline Aspirin & $477(58.8)$ & $568(70.0)$ & $587(72.4)$ & $615(75.8)$ \\
\hline Clopidogrel & $163(20.1)$ & $329(40.6)$ & $338(41.7)$ & $351(43.3)$ \\
\hline Dipyridamole & $34(4.2)$ & $12(1.5)$ & $22(2.7)$ & $31(3.8)$ \\
\hline Cilostazol & $13(1.6)$ & $18(2.2)$ & $20(2.5)$ & $29(3.6)$ \\
\hline Ticlopidine & $12(1.5)$ & $10(1.2)$ & $16(2.0)$ & $20(2.5)$ \\
\hline Warfarin & $33(4.1)$ & $76(9.4)$ & $97(12.0)$ & 109 (13.4) \\
\hline Antihypertensive agent & $599(73.9)$ & $613(75.6)$ & $675(83.2)$ & $703(86.7)$ \\
\hline ACEI & $161(19.9)$ & $144(17.8)$ & $163(20.1)$ & $181(22.3)$ \\
\hline ARBs & $234(28.9)$ & $229(28.2)$ & $261(32.2)$ & $300(37.0)$ \\
\hline CCBs & $348(42.9)$ & $283(34.9)$ & $324(40.0)$ & $371(45.7)$ \\
\hline$\beta$-blockers & $289(35.6)$ & $197(24.3)$ & $314(38.7)$ & $392(48.3)$ \\
\hline Diuretics & $171(21.1)$ & $181(22.3)$ & $210(25.9)$ & $237(29.2)$ \\
\hline a-blockers & $116(14.3)$ & $76(9.4)$ & $105(12.9)$ & $129(15.9)$ \\
\hline Antidyslipidemic agents & $291(35.9)$ & 321 (39.6) & $370(45.6)$ & $410(50.6)$ \\
\hline Statins & $257(31.7)$ & $300(37.0)$ & $349(43.0)$ & $386(47.6)$ \\
\hline Fibrates & $53(6.5)$ & $24(3.0)$ & $31(3.8)$ & $50(6.2)$ \\
\hline Others & $11(1.4)$ & $13(1.6)$ & $14(1.7)$ & $18(2.2)$ \\
\hline Antidiabetic agents & $177(21.8)$ & $144(17.8)$ & $170(21.0)$ & $187(23.1)$ \\
\hline Metformin & $114(14.1)$ & $79(9.7)$ & $96(11.8)$ & $117(14.4)$ \\
\hline Sulfonylureas & $132(16.3)$ & $98(12.1)$ & $107(13.2)$ & $117(14.4)$ \\
\hline Thiazolidinedione (TZD) & $43(5.3)$ & $23(2.8)$ & $31(3.8)$ & $33(4.1)$ \\
\hline DDP-4 inhibitors & $10(1.2)$ & $10(1.2)$ & $16(2.0)$ & $23(2.8)$ \\
\hline Others & $45(5.5)$ & $28(3.5)$ & $38(4.7)$ & $49(6.0)$ \\
\hline Nitrates & $265(32.7)$ & $290(35.8)$ & $350(43.2)$ & $388(47.8)$ \\
\hline Nitroglycerin & $43(5.3)$ & $11(1.4)$ & $27(3.3)$ & $74(9.1)$ \\
\hline Isosorbide dinitrate & $57(7.0)$ & $58(7.2)$ & $75(9.2)$ & $86(10.6)$ \\
\hline Isosorbide mononitrate & $184(22.7)$ & $216(26.6)$ & $246(30.3)$ & $267(32.9)$ \\
\hline Nicorandil & $41(5.1)$ & $24(3.0)$ & $44(5.4)$ & $69(8.5)$ \\
\hline
\end{tabular}

\section{Discussion}

This study included a total of 1397 patients with CAA during 2005-2011. The mean age of our population was $37.76 \pm 31.45$ years. Notably, the age distribution ranged widely from 0 to 91 years in our study, and the pediatric, adult and elderly populations accounted for $41.9,30.8$ and $27.3 \%$ of the total, respectively. In contrast with angiographic series in the literature, we had access to the data of pediatric patients with CAA instead of only adults. The mean age of the pediatric population was $3.16 \pm 3.66$ years, and approximately $69.3 \%$ of the pediatric patients were male.

\section{Comorbidities in pediatric patients}

Most pediatric patients were diagnosed with Kawasaki disease (95.7\%), especially infants 1 year of age and below
(23.2\%), and were under 5 years of age, which was in accordance with epidemiological reports in Taiwan [23-25].

Kawasaki disease is a systemic vasculitis that commonly involves the coronary arteries and is considered the main cause of nonatherosclerotic CAA in young children [20, 22]. From our results, the disease burden of Kawasaki disease in Taiwan and its associated risk for the development of CAA cannot be overlooked. For young patients presenting acute coronary syndrome, such as angina and myocardial infarction, the development of CAA should be considered and patients should receive treatment as soon as possible.

\section{Comorbidities in adult patients}

The mean age of the adult population with CAA was $62.9 \pm 14.1$ years, and the majority of patients were male 


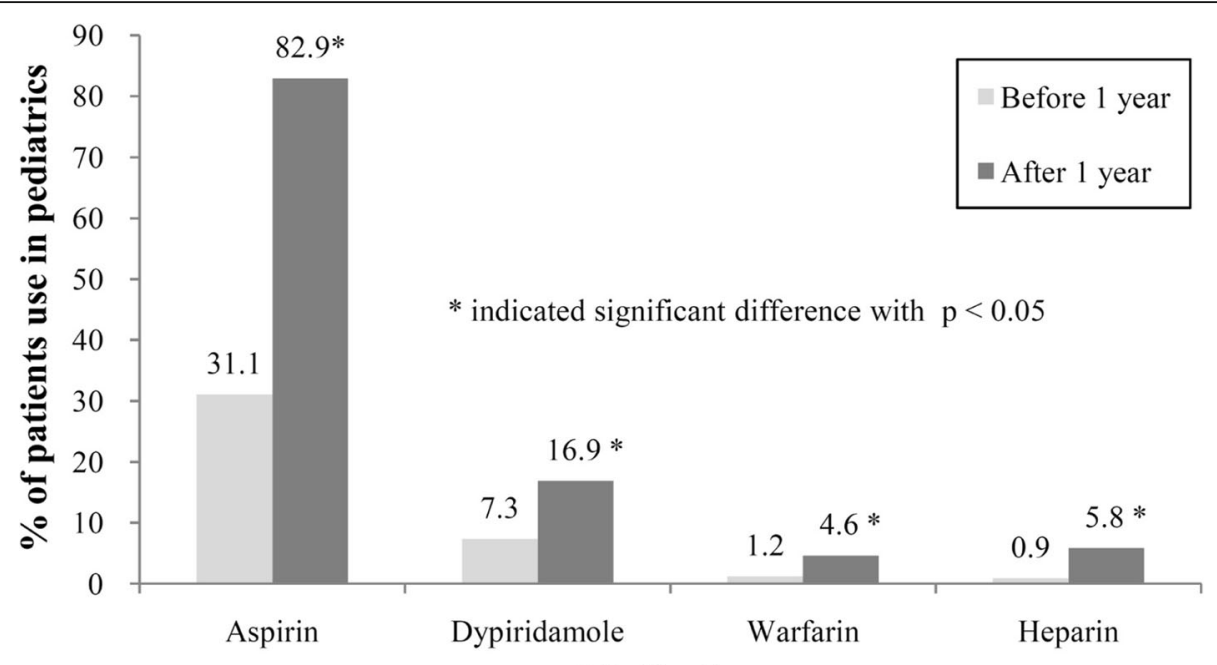

\section{Medication}

Fig. 1 Antithrombotic agents used in pediatric population

(67.9\%). Prevalent coexisting diseases included hypertension (63.4\%), hyperlipidemia (39.6\%), diabetes mellitus (26.1\%) and other chronic diseases. A small proportion of CAA patients had aortic dissection and aortic aneurysm. Most of the comorbidities were diagnosed more frequently after identification of CAA. Remarkably, coronary atherosclerosis was found in $72.5 \%$ of patients after CAA diagnosis.

Atherosclerosis remains the principal cause of CAA in the adult population, even though the exact etiology is still unknown $[22,26]$. Our results showed a high proportion of coronary atherosclerosis (72.5\%) in adults, which was consistent with the literature. With respect to cardiovascular diseases, our patients had a higher incidence of hypertension and diabetes mellitus but a lower incidence of hyperlipidemia than those in other reports in general. The variation may be due to the relatively older age of our population. Hypertension, hyperlipidemia and diabetes mellitus are risk factors known to be associated with atherosclerosis; however, the relationship between risk factors of hypertension, hyperlipidemia, diabetes mellitus and CAA needs to be further investigated.

Previous myocardial infarction and angina were reported in 10.4 and $18.9 \%$ of our population, respectively; these proportions were lower than those in some previous studies [21, 27, 28]. It has been suggested that patients with CAA commonly present with ischemic heart

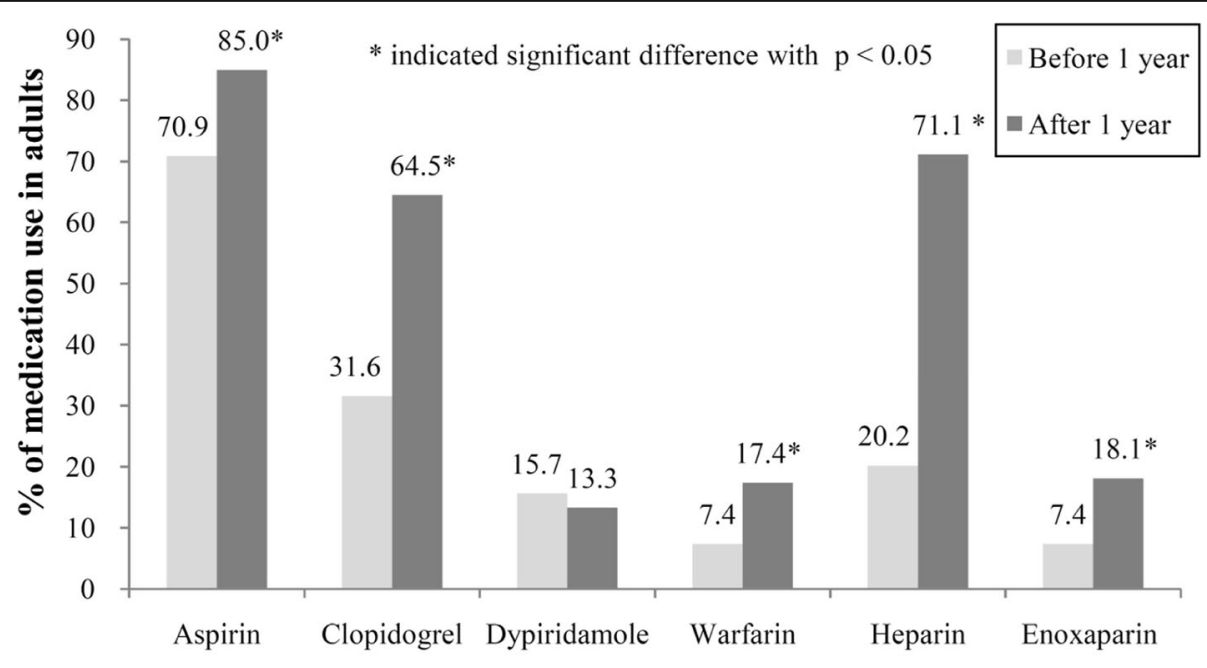

\section{Medication}

Fig. 2 Antithrombotic agents used in the adult population 
disease such as angina pectoris and myocardial infarction. Nevertheless, it was difficult to differentiate whether these symptoms were manifestations of aneurysm or coronary artery disease [22].

\section{Prescribing patterns in pediatric patients}

In the current study, we found an increased utilization of aspirin and gamma globulins in 82.9 and $53.6 \%$ of pediatric patients, respectively, after CAA diagnosis. Among the antithrombotic agents, aspirin was used most frequently, followed by dipyridamole (16.9\%), heparin (5.8\%) and warfarin (4.6). Only 4 patients (0.7\%) received clopidogrel. Since most of the pediatric patients (95.7\%) were diagnosed with Kawasaki disease, antithrombotic treatments were reasonably used in the clinic. On the basis of the recommendations by the American Heart Association (AHA) guidelines [29], aspirin should be administered at a high dosage (80 to $100 \mathrm{mg} / \mathrm{kg} /$ day) with intravenous immunoglobulin (IVIG) in the acute phase because these two medications appear to possess an additive anti-inflammatory effect. However, the duration of high-dose aspirin treatment differs by institution, and most reduce the aspirin dose 48 to $72 \mathrm{~h}$ after fever subsides. In certain cases, the duration may be prolonged to 14 days after Kawasaki disease onset.

Aspirin treatment should be adjusted to a low dosage ( 3 to $5 \mathrm{mg} / \mathrm{kg} /$ day) after the acute phase. Platelet aggregation activity remains high during the first 3 months after Kawasaki disease onset and can even last for 1 year after disease onset in some cases. For patients who develop coronary aneurysm due to Kawasaki disease, aspirin may be continued indefinitely to prevent ischemic heart disease and prevent the formation or growth of thrombi by platelet aggregation based on the Japanese Circulation Society (JCS) guidelines [30]. Suggested antiplatelet agents to be used in children with Kawasaki disease include aspirin, flurbiprofen, dipyridamole, ticlopidine and clopidogrel. Choices for anticoagulant drugs include heparin, low-molecular weight heparin (LMWH) and warfarin. In view of the existing CAAs in our patients with Kawasaki disease, antiplatelet treatment for the prevention of cardiac sequela is reasonable.

\section{Prescribing patterns in adult patients}

Regarding medication use in adult patients, we found that antithrombotic agents, particularly aspirin, clopidogrel and heparin, were prescribed more frequently after CAA diagnosis. Cardiovascular medications, oral antidiabetic agents, lipid-lowering agents and nitrates, were also increasingly prescribed after CAA diagnosis. Among the prescriptions, aspirin (75.8\%), $\beta$-blockers (48.3\%), statins $(47.6 \%)$, metformin (14.4\%), sulfonylureas (14.4\%) and isosorbide mononitrate (32.9\%) were frequently observed in each category. Data regarding prescribing patterns in CAA patients was limited in the previous literature. Most series focused on whether patients received surgery, percutaneous intervention or medical therapy instead of specific drug utilization. Only a few studies reported the prescribing pattern in patients with CAA [31, 32]. Sultana et al. [31] reported that 56, 14 and $70 \%$ of patients were prescribed aspirin, warfarin and a combination of aspirin and warfarin, respectively. Other medications, such as calcium channel blockers (CCBs), $\beta$-blockers and nitrates, were used in 25,20 and $34 \%$ of patients, respectively. A $97 \%$ prescribing rate for aspirin was reported in a series by Almansori et al., [32] in which angiotensin-converting-enzyme (ACE) inhibitors (59\%), angiotensin II receptor blockers (ARBs) (34\%), CCBs (22\%), statins (95\%) and nitrates (49\%) were also recorded. The great variety of prescribing patterns across studies was mainly affected by coexisting diseases. A previous review by Dahhan [33] suggested that the management of coronary artery ectasia should be based on the underlying etiology. The general medical therapy for patients with coronary artery ectasia includes antiplatelet agents, $\beta$-blockers, ACE inhibitor, ARBs, CCBs and statins, especially if another indication is present (e.g., hypertension, dyslipidemia, diabetes mellitus).

Concerning the effect of specific medications, antiplatelets, $\beta$-blockers and statins are indicated for accompanying atherosclerotic coronary artery disease. In addition, other drugs have different indications: anticoagulants for secondary prevention of further thrombosis; dihydropyridine $\mathrm{CCB}$ for the prevention of vasospasm; and ACE inhibitors for decreasing inflammation.

Our study showed that patients under 20 years of age are exposed to acute respiratory infections, noninfectious gastroenteritis and colitis, allergic rhinitis and contact dermatitis very often. There may be a relationship between Kawasaki disease with allergic diseases and this finding is consistent with previous studies [34, 35]. Kawasaki disease were at an increased risk for allergic diseases compared with the comparison cohort and children with Kawasaki disease had a higher risk of developing atopic dermatitis.

In summary, the management of CAA should be tailored to each individual based on the underlying etiology. Our adult population had a significant burden of cardiovascular disease, which indicated that drugs prescribed for such chronic conditions were reasonable.

\section{Limitations}

To the best of our knowledge, this is the first population-based study investigating the comorbidities and prescribing patterns for CAA patients in Taiwan. We enrolled CAA population in Taiwan, with data obtained from the NHIRD. We are able to provide an explicit age 
distribution, including pediatric and adult populations, which was different from previous studies that used an angiographic method to enroll adult patients. However, there were some limitations in our study. First, our data were obtained from a claim-based database, and we did not have information on aneurysm features, including the location, morphology, aneurysm size, number of aneurysms and degree of stenosis. In addition, we could not differentiate between CAAs and coronary artery ectasia in this study. Second, we did not have laboratory or image data to determine the severity of artery stenosis, blood pressure values and hemoglobin A1c levels. Some cardiovascular risk factors, such as smoking and body mass index, were also unavailable in the database.

\section{Conclusion}

Both adult and pediatric CAA patients were surveyed in our study. Kawasaki disease was the main cause of CAA in pediatric patients, and aspirin use was increased after CAA diagnosis. Coronary artery disease was the most common comorbidity in adult CAA patients. The most commonly used antithrombic agent after CAA diagnosis in adults was aspirin.

\section{Abbreviations \\ ACEls: Angiotensin-converting enzyme inhibitors; Angio: Coronary angiography; ARBs: Angiotensin II receptor blockers; Cath: Cardiac catheterization; CCBs: Calcium channel blockers; COPD: Chronic obstructive pulmonary disease; CT: Computed tomography; Echo: Echocardiography; MRI: Magnetic resonance imaging; NHIRD: National Health Insurance Research Databases}

\section{Acknowledgments}

This study was based in part on data from the NHIRD provided by the Bureau of National Health Insurance (BNHI) of the Department of Health and managed by the National Health Research Institutes. The conclusions presented in this study are those of the authors and do not necessarily reflect the views of the $\mathrm{BNH}$, the Department of Health, or the National Health Research Institutes.

\section{Authors' contributions}

$\mathrm{CHL}$ and $\mathrm{KML}$ wrote the manuscript, interpreted the findings and critically edited the manuscript; CYC conceived and designed this study, collected and analyzed the data, and supervised this study; CTF, HMC, YPF, YBH and SCJY contributed conception, critical reviews of the data analyses, and reviewed the manuscript; CWF contributed conception, interpreted the findings, critically edited the manuscript and reviewed the manuscript. All authors have read and approved the final manuscript.

\section{Funding}

The design of the study and collection, analysis, and interpretation of data and editorial writing support was funded by Kaohsiung Armed Forces General Hospital (ZBH107-25)

\section{Availability of data and materials}

The data that support the findings of this study are available from NHIRD, but restrictions apply to the availability of these data, which were used under license for the current study and thus are not publicly available. Data are, however, available from the authors upon reasonable request and with permission of the National Health Insurance Research Institutes.

\section{Ethics approval and consent to participate}

The study was approved by the Institutional Review Board of the Kaohsiung Medical University Hospital (KMUHIRB-EXEMPT (II)-20190008) and Kaohsiung Armed Forces General Hospital (KAFGH 106-039).

\section{Consent for publication}

Not applicable.

\section{Competing interests}

The authors declare no competing interests.

\section{Author details}

${ }^{1}$ Division of Pharmacy, Zuoying Branch of Kaohsiung Armed Forces General Hospital, Kaohsiung, Taiwan. ²Division of Health Technology Assessment, Center for Drug Evaluation, Taipei, Taiwan. ${ }^{3}$ School of Pharmacy, Kaohsiung Medical University, 100, Shiquan 1st Rd., Sanmin Dist.,, Kaohsiung City 80708, Taiwan, Republic of China. ${ }^{4}$ Department of Pharmacy, Kaohsiung Medical University Hospital, Kaohsiung, Taiwan. ${ }^{5}$ Department of Medical Research, Kaohsiung Medical University Hospital, Kaohsiung, Taiwan. ${ }^{6}$ Department of Internal Medicine, Chi Mei Medical Center, Chiali, No.606, Jialixing, Jiali Dist., Tainan City 72263, Taiwan, Republic of China. ${ }^{7}$ Department of Business Management, National Sun Yat-sen University, Kaohsiung, Taiwan.

Received: 2 May 2019 Accepted: 26 July 2019

Published online: 05 August 2019

\section{References}

1. Syed M, Lesch M. Coronary artery aneurysm: a review. Prog Cardiovasc Dis. 1997;40(1):77-84.

2. Swaye PS, Fisher LD, Litwin P, Vignola PA, Judkins MP, Kemp HG, et al. Aneurysmal coronary artery disease. Circulation. 1983;67(1):134-8.

3. Reji $R$, Nguyen M. Medically managed coronary artery aneurysm without concomitant stenosis. BMJ Case Rep. 2018;2018:bcr-2018-224244.

4. Fang $C T$, Fang YP, Huang YB, Kuo CC, Chen CY. Epidemiology and risk factors of coronary artery aneurysm in Taiwan: a population based case control study. BMJ Open. 2017:7(6):e014424.

5. Khouzam RN, Gardner JD, Bomb R, Holden AA. Multi-vessel giant coronary artery aneurysm in an elderly female. Ann Transl Med. 2017;5(10):210.

6. Núñez-Gil IJ, Nombela-Franco L, Bagur R, Bollati M, Cerrato E, Alfonso E, et al. Rationale and design of a multicenter, international and collaborative coronary artery aneurysm registry (CAAR). Clin Cardiol. 2017;40(8):580-5.

7. B M, Yazici HU, Aydar Y, Ovali C, Nadir A. Role of gender in types and frequency of coronary artery aneurysm and ectasia. Medicine (Baltimore). 2016;95(31):e4395

8. Boyer N, Gupta R, Schevchuck A, Hindnavis V, Maliske S, Sheldon M, et al. Coronary artery aneurysms in acute coronary syndrome: case series, review, and proposed management strategy. J Invasive Cardiol. 2014;26(6):283-90.

9. Lanjewar CP, Sharma A, Sheth T. IVUS-guided management of late stent malaposition with peri-stent restenosis with coronary artery aneurysm following drug-eluting stent implantation (paxlitaxel-eluting stent). J Invasive Cardiol. 2009;21:E87-90.

10. Alfonso F, Pérez-Vizcayno MJ, Ruiz M, Suárez A, Cazares M, Hernández R, et al. Coronary aneurysms after drug-eluting stent implantation: clinical, angiographic, and intravascular ultrasound findings. J Am Coll Cardiol. 2009; 53:2053-60

11. Tunick PA, Slater J, Kronzon I, Glassman E. Discrete atherosclerotic coronary artery aneurysms: a study of 20 patients. J Am Coll Cardiol. 1990;15:279-82.

12. Bhindi R, Testa L, Ormerod OJ, Banning AP. Rapidly evolving giant coronary aneurysm. J Am Coll Cardiol. 2009;53(4):372.

13. Chia HM, Tan KH, Jackson G. Non-atherosclerotic coronary artery aneurysms: two case reports. Heart. 1997;78(6):613-6.

14. Dajani AS, Taubert KA, Gerber MA, Shulman ST, Ferrieri P, Freed M, et al. Diagnosis and therapy of Kawasaki disease in children. Circulation. 1993;87: 1776-80.

15. Senzaki $H$. The pathophysiology of coronary artery aneurysms in Kawasaki disease: role of matrix metalloproteinases. Arch Dis Child. 2006:91(10):847-51.

16. Newburger JW, Takahashi M, Burns JC, Beiser AS, Chung KJ, Duffy CE, et al. The treatment of Kawasaki syndrome with intravenous globulin. N Engl J Med. 1986;315(6):341-7. 
17. Gelb BD. Marfan's syndrome and related disorders--more tightly connected than we thought. N Engl J Med. 2006;355(8):841-4.

18. Cohen P, O'Gara PT. Coronary artery aneurysms: a review of the natural history, pathophysiology, and management. Cardiol Rev. 2008;16(6):301-4.

19. Friedman K, Gauvreau K, Hamaoka-Okamoto A, Tang A, Berry E, Tremoulet A, et al. Coronary artery aneurysms in Kawasaki disease: risk factors for progressive disease and adverse cardiac events in the US population. J Am Heart Assoc. 2016;5(9):e003289.

20. Pahlavan PS, Niroomand F. Coronary artery aneurysm: a review. Clin Cardiol. 2006;29(10):439-43.

21. Demopoulos VP, Olympios CD, Fakiolas CN, Pissimissis EG, Economides NM, Adamopoulou $E$, et al. The natural history of aneurysmal coronary artery disease. Heart. 1997;78(2):136-41.

22. Nichols L, Lagana S, Parwani A. Coronary artery aneurysm: a review and hypothesis regarding etiology. Arch Pathol Lab Med. 2008;132(5):823-8.

23. Chang LY, Chang IS, Lu CY, Chiang BL, Lee CY, Chen PJ, et al. Epidemiologic features of Kawasaki disease in Taiwan, 1996-2002. Pediatrics. 2004;114(6): e678-82.

24. Huang WC, Huang LM, Chang IS, Chang LY, Chiang BL, Chen PJ, et al. Epidemiologic features of Kawasaki disease in Taiwan, 2003-2006. Pediatrics. 2009;123(3)::401-5. 22.

25. Lin MC, Lai MS, Jan SL, Fu YC. Epidemiologic features of Kawasaki disease in acute stages in Taiwan, 1997-2010: effect of different case definitions in claims data analysis. J Chin Med Assoc. 2015;78(2):121-6.

26. Boles U, Eriksson P, Zhao Y, Henein MY. Coronary artery ectasia: remains a clinical dilemma. Coron Artery Dis. 2010;21(5):318-20.

27. Pinar Bermúdez E, López Palop R, Lozano Martínez-Luengas I, Cortés Sánchez R, Carrillo Sáez P, Rodriguez Carreras R, et al. Coronary ectasia: prevalence, and clinical and angiographic characteristics. Rev Esp Cardiol. 2003;56(5):473-9

28. Valente S, Lazzeri C, Giglioli C, Sani F, Romano SM, Margheri M, et al. Clinica expression of coronary artery ectasia. J Cardiovasc Med (Hagerstown). 2007; 8(10):815-20.

29. Newburger JW, Takahashi M, Gerber MA, Gewitz MH, Tani LY, Burns JC, et al. Diagnosis, treatment, and long-term management of Kawasaki disease: a statement for health professionals from the committee on rheumatic fever, endocarditis and Kawasaki disease, council on cardiovascular disease in the young, American heart association. Circulation. 2004;110(17):2747-71.

30. JCS Joint Working Group. Guidelines for diagnosis and management of cardiovascular sequelae in Kawasaki disease (JCS 2013). Circ J. 2014;78(10): 2521-62.

31. Sultana R, Sultana N, Ishaq M, Samad A. The prevalence and clinical profile of angiographic coronary ectasia. J Pak Med Assoc. 2011;61(4):372-5.

32. Almansori MA, Elsayed HA. Coronary artery ectasia - a sample from Saudi Arabia. J Saudi Heart Assoc. 2015;27(3):160-3.

33. Dahhan A. Coronary artery ectasia in atherosclerotic coronary artery disease, inflammatory disorders, and sickle cell disease. Cardiovasc Ther. 2015;33(2):79-88.

34. Kuo H-C, Chang W-C, Yang KD, Yu H-R, Wang C-L, Ho S-C, Yang C-Y. Kawasaki disease and subsequent risk of allergic diseases: a populationbased matched cohort study. BMC Pediatr. 2013;13:38.

35. Woon PY, Chang WC, Liang C-C, Hsu CH, Klahan S, Huang Y-H, Chang W-P, Kuo H-C. Increased risk of atopic dermatitis in preschool children with Kawasaki disease: a population-based study in Taiwan. Evid Based Complement Alternat Med. 2013;2013:605123.

\section{Publisher's Note}

Springer Nature remains neutral with regard to jurisdictional claims in published maps and institutional affiliations.

Ready to submit your research? Choose BMC and benefit from:

- fast, convenient online submission

- thorough peer review by experienced researchers in your field

- rapid publication on acceptance

- support for research data, including large and complex data types

- gold Open Access which fosters wider collaboration and increased citations

- maximum visibility for your research: over $100 \mathrm{M}$ website views per year

At BMC, research is always in progress.

Learn more biomedcentral.com/submissions 